\title{
Erratum: Field-dependent surface resistance for superconducting niobium accelerating cavities [Phys. Rev. Accel. Beams 14, 101002 (2011)]
}

\author{
Wolfgang Weingarten๑
}

(Received 19 April 2021; published 23 June 2021)

DOI: 10.1103/PhysRevAccelBeams.24.069902

The Erratum concerns the "Cooper limit" formula, Eq. (43), for the superconducting (sc) coupling constant $(N V)_{\text {eff }}$. This formula describes the boundary effect for the mixture of niobium and niobium monoxide in close proximity,

$$
(N V)_{\mathrm{eff}}=\frac{(N V)_{\mathrm{N}} N_{\mathrm{N}} v_{\mathrm{N}}+(N V)_{\mathrm{S}} N_{\mathrm{S}} v_{\mathrm{S}}}{N_{\mathrm{N}} v_{\mathrm{N}}+N_{\mathrm{S}} v_{\mathrm{S}}}
$$

Here $(N V)_{\mathrm{S}}$ is the sc coupling constant of the "strong" (S) superconductor $\mathrm{Nb},(N V)_{\mathrm{N}}$ is that of the "weak" $(\mathrm{N})$ superconductor $\mathrm{NbO}$, and $v_{\mathrm{S}}$ and $v_{\mathrm{N}}$ are the volume densities of the respective components $\mathrm{S}$ and $\mathrm{N}$ within the mixture. $N_{\mathrm{S}}$ and $N_{\mathrm{N}}$ are the "electron density of states" (DOS), in units $\mathrm{of} \mathrm{eV}^{-1} \mathrm{~m}^{-3} \cdot N_{\mathrm{S}}$ and $N_{\mathrm{N}}$ were intentionally referred to as the "electron densities" of the respective superconductors in units of $m^{-3}$, so that they were claimed to be numerically identical to the DOS, but no justification was provided.

In the following, as a justification, $(N V)_{\text {eff }}$ is reevaluated using new data that appeared after publication of this paper [1,2]. Note that neither the absolute values of $N_{\mathrm{S}}$ and $N_{\mathrm{N}}$ nor those of the volume densities $v_{\mathrm{S}}$ and $v_{\mathrm{N}}$ are critical, but their relative values, $N_{\mathrm{N}} / N_{\mathrm{S}}$ and $v_{\mathrm{N}} / v_{\mathrm{S}}$ [cf. Eq. (1)], as published by one single author team, thereby increasing reliability. From $(N V)_{\text {eff }}$ follows the critical temperature $T_{\mathrm{cNS}}$ of the mixture $\mathrm{Nb} / \mathrm{NbO}$ as a function of the relative composition $x=v_{\mathrm{S}} /\left(v_{\mathrm{S}}+v_{\mathrm{N}}\right)$ :

$$
T_{\mathrm{cNS}}=1.14 \Theta_{D} e^{-1 /(N V)_{\mathrm{eff}}(x)},
$$

shown in Fig. 1. $\theta_{D}$ is the Debye temperature of the more abundant component of the mixture, $\mathrm{NbO}\left(\theta_{D}=472 \mathrm{~K}\right)$. The data used are summarized in Tables I and II.

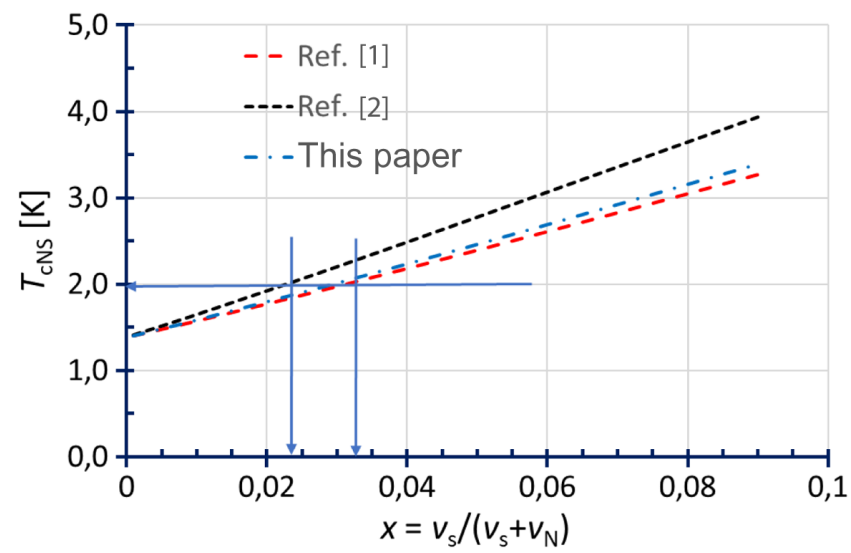

FIG. 1. Critical temperature of the $\mathrm{Nb} / \mathrm{NbO}$ composite in the Cooper limit of the proximity effect vs the volume fraction $x=$ $v_{\mathrm{S}} /\left(v_{\mathrm{N}}+v_{\mathrm{S}}\right)$ of the $\mathrm{S}$ component $(\mathrm{Nb})$.

Published by the American Physical Society under the terms of the Creative Commons Attribution 3.0 License. Further distribution of this work must maintain attribution to the author(s) and the published articles title, journal citation, and DOI. 
TABLE I. Electron densities $n$ of $\mathrm{Nb}$ and $\mathrm{NbO}$.

\begin{tabular}{lccc}
\hline \hline & $\mathrm{Nb}$ & $\mathrm{NbO}$ & $\mathrm{g}$ \\
\hline$A$ & 92.9 & 108.9 & $g / \mathrm{cm}^{3}$ \\
$\rho_{m}$ & 8.57 & 7.3 & $\mathrm{Nb}-\mathrm{atoms} / \mathrm{cm}^{3}$ \\
$n$ & $5.55 \times 10^{22}$ & $4.04 \times 10^{22}$ & \\
& & $n=0.6022 \times 10^{24} \times \rho_{m} / A$ & \\
& & $A:$ atomic weight, $\rho_{m}:$ mass density & \\
& & & \\
\hline \hline
\end{tabular}

TABLE II. Density of states (DOS) of $\mathrm{Nb}$ and $\mathrm{NbO}$.

\begin{tabular}{lccr}
\hline \hline $\mathrm{Nb}(\mathrm{S})$ & $\mathrm{NbO}(\mathrm{N})$ & Unit & $\mathrm{N}_{\mathrm{N}} / \mathrm{N}_{\mathrm{S}}$ \\
\hline $1.3^{\mathrm{a}}$ & $0.55^{\mathrm{b}}$ & States $/(\mathrm{Nb} \cdot \mathrm{eV})$ & \\
$7.22 \times 10^{22}$ & $2.22 \times 10^{22}$ & Nb-atoms $/\left(\mathrm{eV} \cdot \mathrm{cm}^{3}\right)$ & 0.31 \\
$1.8^{\mathrm{c}}$ & 0.4 & States $/ \mathrm{eV}$ & 0.22 \\
$5.56 \times 10^{22 \mathrm{~d}}$ & $1.60 \times 10^{22}$ & Electrons $/\left(\mathrm{eV} \cdot \mathrm{cm}^{3}\right)$ & 0.29 \\
\hline \hline
\end{tabular}

${ }^{\mathrm{a}}$ Reference [1].

${ }^{\mathrm{b}}$ This number concerns the $\mathrm{Nb}_{3} \mathrm{O}_{3}$ structure, not the hypothetical $\mathrm{Nb}_{4} \mathrm{O}_{4}$ structure.

${ }^{\mathrm{c}}$ Reference [2].

${ }^{\mathrm{d}}$ This paper.

It can be seen from Fig. 1 that the experimentally determined percolation temperature $T^{*}=2 \mathrm{~K}$ corresponds to a critical mixture $x^{*}$ in the interval of $2.3 \%$ to $3.3 \%$. This interval includes the critical mixture $\left(x^{*}=3.01 \%\right)$ of this paper.

Since the publication of this paper, another paper dealing with percolation through voids around overlapping spheres appeared [3], as a supplement to Ref. [4]. Ref. [3] gives a wider interval for the critical mixing, about $2.5 \%$ to $4.5 \%$, which agrees quite well with the above results. Therefore, these results are not contradictory.

Therefore, the modification of Eq. (43), as described above, has no significant effect on the value of $(N V)_{\text {eff }}$.

[1] A. K. Efimenko, N. Hollmann, K. Hoefer, J. Weinen, D. Takegami, K. K. Wolff et al., Phys. Rev. B 96, 195112 (2017).

[2] N. N. Ha, Opt. Spectrosc. 115, 233 (2013).

[3] D. J. Priour, Jr., Phys. Rev. E 89, 012148 (2014).

[4] M. D. Rintoul, Phys. Rev. E 62, 68 (2000). 